J O U R N A O F French and Francophone Philosophy
RE V UE DE LA

philosophie française et de langue française

\title{
From Perception to Subject: The Bergsonian Reversal
}

Messay Kebede

Journal of French and Francophone Philosophy - Revue de la philosophie française et de langue française, Vol XXII, No 1 (2014) pp 102-123.

\author{
Vol XXII, No 1 (2014) \\ ISSN 1936-6280 (print) \\ ISSN 2155-1162 (online) \\ DOI $10.5195 /$ jffp. 2014.645 \\ www.jffp.org
}

\section{(c) EY-NC-ND}

This work is licensed under a Creative Commons Attribution-Noncommercial-No Derivative Works 3.0 United States License.

\section{ULIS D-Sult}

This journal is operated by the University Library System of the University of Pittsburgh as part of its D-Scribe Digital Publishing Program, and is co-sponsored by the University of Pittsburgh Press 


\title{
From Perception to Subject:
}

\section{The Bergsonian Reversal}

\author{
Messay Kebede \\ University of Dayton
}

\section{From Perception to Subject: The Bergsonian Reversal}

What singles out philosophical analyses of perception is the challenge to common sense, that is, to the spontaneous, instinctive belief that an external world exists and that it is similar to the perception we have of it. Even those theories that refrain from questioning the independent existence of the world concede that the resemblance of whatever is out there to the perceived reality is anything but assured. Henri Bergson proposes a theory of perception that not only restores the common belief in the existence of an external world, but also goes a long way in narrowing the alleged disparity between perception and the objective world. With few exceptions, Bergson's theory of perception has been either ignored or misunderstood. Through a close reading of the first chapter of Matter and Memory, the paper argues, in addition to correcting misreadings, that the strength and originality of Bergson's theory lie in the reversal of the method of explaining perception from the premise of a given subject, a premise shared by all idealist and realist theories as well as phenomenology. This de-subjectification proposes an approach deriving perception from the interactions of objects while countering the materialist theory of the brain as an organ of representation. The paper contends that the Bergsonian elucidation of the brain as an organ of simulation both anticipates the findings of the sensorimotor theory and overcomes its limitation by showing how simulation inserts indetermination into materiality, thereby actualizing consciousness.

\section{Contradictions of Representational Theories of Perception}

The perception of objects presents the characteristics of being external, extended, and qualitatively differentiated. At the same time, it is equally true that external objects are just a set of ideas in the mind of the perceiver. From the inescapable fact that the mind knows only its own ideas, the 
idealist thinker draws the conclusion that the path of consistency is to maintain that the world is nothing but my own representation. George Berkeley, an authoritative proponent of the idealist position, finds the belief that objects exist independently of the perceptions that we have of them contradictory. He asks: "What are the fore-mentioned objects but the things we perceive by sense? and what do we perceive besides our own ideas or sensations? and is it not plainly repugnant that any one of these, or any combination of them, should exist unperceived?"1

Consistency does not shield the idealist position from being utterly untenable. True, the idealist assumption explains why perception is a centered system in which things vary according to the movements of the perceiving subject. All the same, the explanation cannot deny that, though the subject occupies the center, the things that surround it are governed by laws independent of the will of the perceiver. This recognition forces the idealist "to abandon this central position, to replace all the images on the same plane, to suppose that they no longer vary for him, but for themselves."2 Some such admission turns idealism into realism, that is, into a defense of the belief that reality exists independently of the perceiver. But given that idealists cannot have recourse to the concept of matter to establish the independence of perceived objects, they have to appeal to some deus ex machina. Thus, to explain the permanence and regularity of his perceptions, Berkeley could find no other solution than to pinpoint God as the direct cause of his ideas and His benevolence as the reason for their ordered course.

Though unlike idealists, realists admit the independent existence of things, their theory of perception is no less contradictory. Since realists are convinced that perception is representation, they feel compelled to clearly separate the subjective from the objective, that is, what appears in the mind from what is external to the mind. This way of positing the problem contains the quagmire in which realists find themselves. Since for them the real is the world where things are governed by objective laws, the centered and variable system of perception cannot be anything other than appearance. On the other hand, realists concede that only the world of perception is given so that the real world, the world behind our perceptions is either posited by means of arbitrary "metaphysical construction" or is declared "unknowable" in the fashion of Kant or Hume. ${ }^{3}$ An instance of metaphysical construction is Descartes's argument that perceptions, despite their subjective nature and provided they are distinct and clear, can be said to correspond to material objects on account of God being not "a deceiver." 4 What is more, the purification of perception from all that is exclusively subjective results in the reduction of material objects to pure extension, which reduction has little to do with the qualitative nature of my perception.

It must not be made to seem that the materialist version of realism is in a better shape in its dealing with the existence of a material world. Insofar as 
the materialist credo reduces the real to materiality, its theory of perception entirely rests on a substitution: what for dualists is the distinct function of a spiritual agent is passed on to the brain--a material object among other material objects--which is then endowed with the occult and unknowable power of "engendering representations." ${ }^{5}$ Moreover, because it is said that, instead of the mind, the brain produces the representation of objects, the problem is nowhere near to being solved: perception still remains drowned in subjectivism and the materialist ends up, just as the idealist, with the affirmation that the world is nothing but his/her representation.

The major contradiction of dualistic and materialist representational theories of perception is that their conclusion leans toward the idealist standpoint despite their initial rejection of it. As to idealism, it refuses the point of departure of realism but only to move toward it as soon as it wants to explain why perceived things are independent of the will of the perceiver. The source of these contradictions is to be found in the stubborn idea of lodging perception in the subject, be it in the brain or in the mind, thereby locking up perception in an insurmountable subjectivism. The consequence is that the existence of an independent world and the confidence that things look like the perceptions we have of them turn into intractable problems. In truth, the predicaments of representational theories should not come as a surprise: the idea of engendering the representation of the external world, not from the world itself but from the brain or the mind of the perceiver, seriously muddles the notion of externality from the get-go. If the representation of an object is in the brain or the mind, then the externality of the object can be established only by unconvincing intellectual artifices.

\section{The Two Systems and the Practical Function of Perception}

Since the contradictions of realist and idealist theories of perception show that the attempt to deduce the objective system of matter from the centered system of perception or vice versa is at an impasse, Bergson invites us to admit that "each of them is sufficient to itself." 6 So posited, the problem of perception is no longer how internal representations reproduce the objective world. Rather, it is to explain how the same objects can belong to two different systems: (1) the objective system where things are given as external to one another and are governed by objective laws, thereby forming an independent world; (2) the system of perception in which the same objects exist for and vary according to the perceiving subject.

The same objects can belong to two different systems only if the centered system, instead of being a copy, a transmutation of the material into a mental duplicate (realism) or an absolute excluding the unperceived (idealism), is just a limitation of the uncentered and objective system. Such an approach does no more than drop all representational theories of perception in favor of a theory attributing the system of perception to a 
selective act. The immediate implication of this theory is that there is no difference in kind between perceived things and things in themselves. While all representational theories cannot avoid opposing appearance to reality, for Bergson, perceived things are not subjective entities, but selected things, that is, things turned toward us instead of being turned toward each other. The difference between perception and reality is not one of appearance versus reality, but simply one of part and whole.

What could be the function of the centered system as opposed to the uncentered system? When we contrast the system of matter in which objects act and react in a necessary way with the centered system of perception in which things vary in relation to a central object, both the variation and the selected nature of the centered system suggest that its purpose is to allow actions emanating from the center. In the system of matter, to the extent that actions and reactions are automatic, a centered system is utterly superfluous owing to the absence of autonomous reactions. The appearance of a centered and selected system presupposes, therefore, the withholding of automatism in favor of objects displaying themselves for an autonomous agent.

The definition of perception as selection brings about a crucial change of perspective. All idealist and representational theories work with the assumption that perception induces a speculative attitude toward objects. As Bergson puts it, their common postulate is that "perception has a wholly speculative interest; it is pure knowledge."7 Indeed, when idealists and realists conceive of perception as a subjective picture, is it not to endow it with a cognitive function? Other than providing knowledge about external objects, of what use would mental duplicates be? The only difference is that realists consider perception as confused knowledge, as opposed to science, which studies things as they are, and not as they appear, while idealists see perception as an authentic revelation of what is given and science as a mere symbolic or useful expression.

In contrast to the traditional assumption-with the notable exception of the pragmatist school, which, like Bergson, maintains that perception must be understood in terms of action-to approach perception from the perspective of selection involves action and action alone. Perception serves action only if it adjusts the world to the practical needs of an active agent. In order to do so, perception must be part of things rather than being a speculative view, taking place in the subjective realm of the perceiver. In effect, as the act of selecting, perception reveals what interests our action and leaves out what is of no interest. It does so, not by a process of knowledge reproducing subjectively the environment, but by displaying what is of interest while the rest remains in the dark or is unperceived. In other words, perception is not so much representation as presence or manifestation. Granted, both the French text of Bergson's Matter and Memory and its English translation use the term "representation," but it must be understood as presence, revelation, and not as mental duplicate. The " $\mathrm{re}^{\text {" in }}$ 
representation means what comes out subsequent to a sorting out, as will be elaborated in the following pages.

The confusion between perception and knowledge, between presence and representation (in the sense of duplication) comes from the fact that higher intellectual faculties and, notably, memory always fuse with the raw material of perception. By inserting past images into the present, memory incorporates recognition into perception, and so converts presence into representation. The mixture induces the wrong belief that perception takes place inside us instead of being inside things. In short, memory subjectivizes perception and explains the transition from what Bergson calls "pure perception" to "concrete perception." As one scholar writes, "the true subjective consciousness belongs solely to memory for Bergson. Only with the injection of memories of the past in the apprehension of a present object does the perception become a properly mental event with a subjective and individual hue." ${ }^{8}$ More will be said about the role of memory in the last paragraph.

\section{Matter and Perception}

That the selective nature of perception guarantees the reality of what is perceived entails that the characteristics of perception are attributable to matter. And since the consensus is that material objects are perceived as images, the logical conclusion is that matter itself is just an ensemble of images. To quote Bergson, "I call matter the aggregate of images, and perception of matter these same images referred to the eventual action of one particular image, my body." 9

Both idealism and realism admit that material objects are given as images, to wit, as picturesque representations defined by size, shape, position, colors, sounds, etc. Disagreements arise, not on the fact that things appear as images, but on the question whether images exhaust the reality of what is perceived (idealism) or are mental duplications of something different (realism). What we have said so far establishes against realism and idealism that reality is neither duplicated nor reduced to the perceiving mind. To say so is to reject both the separation between appearance and reality and the shrinkage of reality to the perceived; it is to ascertain that the perceived and the object are one and the same, and hence that the object in itself is an objectively existing image. For Bergson, this is exactly how common sense conceives of material objects: "the object exists in itself, and, on the other hand, the object is, in itself, pictorial, as we perceive it: image it is, but a self-existing image." 10

Berkeley, too, is of the opinion that his theory of perception agrees with common sense, with the idea that things are exactly how we perceive them. However, Berkeley departs from common sense when he concludes that "to 
be is to be perceived." For common sense, not only things are exactly how we perceive them, but they also remain so even when we do not perceive them. Things exist as unperceived images, a view Bergson endorses by saying that "an image may be without being perceived; it may be present without being represented."11

Bergson's definition of matter as an ensemble of images suggests an affinity, a lineage between materiality and consciousness. It affirms that perceived and unperceived material objects are essentially of the same nature, the perceived being simply a cut from the whole. Specifically, to extend the characteristics of perception to material objects means that no less than the so-called primary qualities (extension, figure, movement, and solidity), secondary qualities (color, sound, smell, taste) belong to matter. The conception does away with traditional dualism according to which "in consciousness there would only be images-these were qualitative and without extension. In space there would only be movements - these were extended and quantitative."12 In testifying that matter is qualitatively differentiated, perception extends the indivisibility of consciousness to matter as well, so that what appears divisible, distinct, and juxtaposed to other objects is just a piece cut out from the fundamental "continuity of the extended."13 If to perceive is to put a portion into relief, then the portion belongs to a whole that it is both continuous and differentiated.

The affinity between matter and what is perceived, the conception, therefore, that "things are of the same nature as perception" retains the strengths of realism and idealism while avoiding their mistakes. ${ }^{14}$ It says that realism is right in positing an objective world, an independent reality, but wrong when it equates independence with being alien to consciousness. On the other hand, the affinity with consciousness rescues the idealist belief that the perceived is not a copy of reality, without however confining reality to the perceiving mind.

According to the traditional approach, conscious perception reveals what basically is incapable of revealing itself. In conceiving things as images, Bergson rejects the assumed opacity of matter. That is why, unlike Berkeley, an image does not need a subject to exist on its own. Materiality is appearance that does not require a subject, for otherwise unperceived things would not exist as images. Since each image receives the influence of all other images and reacts, it is by definition manifestation, appearance. An image is not a self-contained entity, a substance; it is strictly identical to the actions it receives and to the reactions it opposes In a word, it is "merely a road by which pass, in every direction, the modifications propagated throughout the immensity of the universe." ${ }^{15}$ As a product of action and reaction, an image is a phenomenon; its essence is to manifest, shine. The condition for objects to look like the perceptions we have of them is that their existence is their manifestation, and not their being entities, which would exist without appearing. Since in the system of necessity everything 
exists owing to interaction, being image is an intrinsic property of materiality.

To elaborate further, the definition of things as images implies that things themselves have the being of perception. To say otherwise would be to reintroduce the distinction between being and appearance. How could there be identity between the image and the image perceived unless the nature of the image agrees with that of perception? We saw that being nothing more than the sum of the influences that it receives and the reactions that it opposes, an image exists, not a self-contained entity, but as manifestation, appearance. An object does not transit from the status of nonimage to that of appearance by an external device. To appear is exactly its existence or the way it exists. When a thing owes its being to action and reaction, its existence cannot be that of a substance, of something closing, withdrawing within itself. Since its existence depends on action and reaction, it has the being of appearance. To use an analogy, an image exists in the same way as the location of intersecting beams of light appears. If materiality is defined by action and reaction, nothing in it possesses the character of being self-contained or of "being-in-itself," to borrow the language of phenomenology. In other words, Bergson throws out the whole tradition of identifying materiality with being-in-itself: a material object is not an independent, self-contained existence; rather, its existence is relational, and as such it exists as appearance or image. The fact that the object exists as appearance, and not as a substance, establishes that it has the same status as perception, which, everybody agrees, is just appearance. The way the object appears to perception is exactly how it comes into being. Consequently, the question is no longer why things appear, but under what conditions appearance turns into a conscious perception.

Bergson reminds us that the choice is never between defining matter in terms of image or not. In whichever way the definition is devised, it must involve something that it is perceivable. No matter the defining element (atom, force, wave, energy, light, etc.), it must be "determined in relation to an eventual vision and an eventual contact." 16 The inevitability of the determination of matter by something perceivable is how it is conceived in terms of image, which conception presupposes a kinship between matter and consciousness. One cannot defend the veracity of the definition without at the same time assuming the objectivity of what is perceived as image.

The approach conceding the latency of consciousness in matter escapes the impossible task of deducing consciousness from what is absolutely devoid of consciousness. The rejection that things are images in themselves only leads to the impasse that images have just a subjective existence. Nothing is then left but the theory of the brain producing consciousness, which as we saw is a magical explanation. It is indeed magic to believe that a thing previously defined as totally stranger to consciousness could somehow produce it. As to dualism, it does not offer a better alternative: the 
idea of placing images in the mind entails the subjectivity of images, and hence an unbridgeable gap between matter and perception. For Bergson, only the definition of matter as an aggregate of images can put to rest both the materialist project of deducing consciousness from that which by definition is alien to it and the dualist attempt to unite completely antithetical substances. As Jean-Paul Sartre puts it, according to Bergson, "there is no need to derive consciousness...since to posit the material world is to have a collection of images." 17

The question of how Bergson accounts for perception without positing an a priori subject points to the insertion of choice into determinism. The operation invites the understanding of the conversion of images into possible actions as a manifestation of impersonal consciousness. What follows must therefore elucidate successively the following issues: first, the notion of impersonal consciousness; second, the mechanism of selection and presentation of images; third, the process by which the impersonal becomes the perception of a distinct subject.

\section{The Idea of Impersonal Consciousness}

The theory that things are images and that they are perceived where they are and as they are, while it definitely overcomes the difficulties of dualism by positing an affinity between matter and consciousness, raises the huge problem of the distinction between the perceived and the perceiving subject. The problem is the very one that Sartre throws at Bergson when he asks, "how this unconscious, impersonal consciousness becomes the conscious consciousness of an individual subject. How do virtually represented images suddenly manage to encompass an ' $\mathrm{I}$ ' by becoming present?" ${ }^{18}$ For Sartre, the identification of matter with images, insofar as it conflates being with consciousness and compels us to speak of unconscious, impersonal consciousness, is a theoretical deadlock. It overlooks that the fundamental character of consciousness is to be transparent to itself, as opposed to the absolute opacity of objects: because it is always consciousness of something, it can never be an object for itself.

The riddle here is that Bergson and phenomenology agree on the substantial issue, namely, that perception excludes having images in the mind so that things are perceived outside, where they are. In agreement with Bergson's analysis, Sartre's intentional consciousness transcends itself and reveals objects directly, without the mediation of internal images. ${ }^{19}$ Moreover, intentionality, the act of aiming at something objective upholds the Bergsonian idea of perception as selection or extraction from a much vaster field of objects. Nonetheless, the agreement is obtained through irreconcilable means: for Bergson, the externality of the perceived derives, not from the intentionality of consciousness, but from the objective interactions of images. What this means is that, though phenomenology 
constitutes a radical departure from the traditional position, Bergson's rupture with tradition is even more radical.

For Bergson, the distinction between subject and object cannot be posed in terms of opposition, as is still the case with the Sartrean dualism of being and nothingness, because matter and consciousness are not alien entities. Accordingly, what makes things perceivable is no longer the subject, but the very characteristic of things. Rather than things becoming perceivable as a result of the action of an external subject, they offer themselves as perceivable. What we have said so far about images entails that things let themselves be perceived, that their being images implies the intrinsic property that they exist inasmuch as they reveal themselves. The passage from appearance to presence, that is, to being consciously perceived, adds nothing to images. As we shall see soon, it simply results from an alteration in the way images interact.

Granted that the fact of consciousness of being always consciousness of something clearly separates subject and object, the fact remains that intentionality does not eliminate the subjectivity of perception. What defeats the elimination is the separation of consciousness and the object it aims at: intentionality is how consciousness is always outside of itself, but it is also how it never coincides with the object. For Bergson, by contrast, as forcefully implied in the characterization of material objects as images, there is "coincidence" between consciousness and the object perceived. ${ }^{20}$ It is just that there is no way of avoiding subjectivism if conscious perception is the act of a subject instead of being an outcome of the interactions of images.

For perception to be indeed an objective revelation, that is, for things to be perceived as they are and where they are, there is only one condition: perception must occur in things themselves rather than consciousness revealing things. Gilles Deleuze demarcates phenomenology from Bergsonism by opposing the expression "all consciousness is something," which would be proper to Bergson, to the phenomenological formula of "all consciousness is consciousness of something." 21 The latter maintains a distinction between the perceiver and the perceived; that of Bergson erases the distinction. Consciousness is not aiming at; it is the thing itself, more exactly, the thing revealed. Clearly, Bergson's position breaks with the whole philosophical tradition according the sole function of revealing, of drawing things out of their ontological darkness, like a flashlight illuminates objects in a dark room, to the conscious subject. For Bergson, the reverse is true: "consciousness is a luminosity which goes from the thing to the subject," says Sartre. ${ }^{22}$ In fact, Sartre's comment falls short of exactitude by implicating a subject: the process is best rendered "by analogy as selfperception of matter." 23

The sticking point between Bergson, phenomenologists, and dualists, is the issue whether consciousness exists only as subject. The reduction of 
consciousness to cogito totally rejects the idea of impersonal consciousness. Yet, if we ask the question of knowing which of the two positions relies on the least postulates, the answer is obvious. Bergson's critics start with selfconsciousness, which they take for granted, whereas Bergson wants to derive it from an impersonal function. Far from being a given, the personalized consciousness is an outcome of a process involving the centered activity of the body and the continuity of memory. The theory that attempts the genesis of the subject from materiality itself is more likely to avoid the predicaments of dualism.

More importantly, the positing of impersonal consciousness alone guarantees the objectivity of perception. To consider self-consciousness as the only and exclusive form of consciousness is to insert between the object and perception the unbridgeable gap separating that which is conscious from that which is devoid of consciousness. Defending phenomenology, Renaud Barbaras sees a contradiction between Bergson's definition of matter as an ensemble of images and his attempt to deduce subjectivity. The definition, he says, presupposes a subject, obvious as it is that one cannot speak of image "without a subject that conditions it." 24 Precisely, if the image, instead of being an image in itself, is conditioned by the subject, the image and the thing no longer coincide and the objectivity of perception is lost for good. The only way by which perception can be clear of subjectivism is through the assumption that self-consciousness emerges from a more primitive form of consciousness inherent in materiality itself. In a nutshell, Bergson and phenomenology agree that things are perceived where they are; however, Bergson adds that they are also perceived as they are because they are images.

What the identity between object and perception underlines is the system of action, the practical connection of the living body with the environment. As we saw, the system is prior to knowledge, that is, to the distinction between subject and object. In the practical system, the environment and the living body, which occupies the center, constitute a circuit, and so belong to the same conscious system. We do not have here a one-sided process where a conscious subject unilaterally aims at objects, but a system that is both centered and an encompassing whole of interacting images, the only difference from the system of matter being that the necessity of action and reaction is converted into the possible actions of a central image. Bergson finds that experience confirms the impersonal nature of perception: "psychologists," he says, "who have studied infancy are well aware that our representation is at first impersonal. Only little by little, and as a result of experience, does it adopt our body as a centre and become our representation." 25 Without overlooking important differences, the role that Bergson attributes to experience and memory in the formation of the self comes close to the position of an empiricist like John Locke, who bases personal identity on "the same continued consciousness." 26 The Bergsonian 
idea of a genesis of the self from impersonal consciousness should not be harder to accept than the empiricist assumption of a tabula rasa mind, whose lack of content signifies an initial impersonal mind.

Before dealing with the process of conscious perception, we must settle one issue, to wit, whether placing perception in things themselves does not amount to a form of animism. Maurice Merleau-Ponty alludes to those critics who accused Bergson of being "an animist," because "his universe of images was an ensemble of representations without a subject, and that he gave himself a diffuse consciousness floating in the things." 27 The accusation seems to stem from an inability to understand the originality of Bergson's theory in that it overlooks some points that are both glaring and fundamental. First of all, perception implies, as already stated, a circuit so that the conscious dimension is confined neither to the perceiver nor to the perceived; it simply reveals their dynamic relation. Second, the images that protrude as distinct objects have no real existence, since they are artificial cuts for the purpose of action in the moving continuity. Accordingly, as already stated, individualized objects are not entities or do not have a distinct existence, let alone having souls. What is real is the continuity of matter in which consciousness inheres as a neutralized property actualized only by the living body. Third, Bergson wants to overcome the difficulties of dualism by avoiding the conception of consciousness as something opposed and external to matter in favor of an approach that shows spirit growing out from materiality through a process of differentiation. Rather than sticking to the impasse of an original opposition, differentiation starts with a primitive unity and explains the emergence and autonomy of spirit by the activation of qualitative differences.

\section{The Role of the Brain}

The impersonal or objective nature of perception is what Bergson calls "pure perception," which he defines as "the lowest degree of mind---mind without memory--" and adds that it "is really part of matter." 28 On the other hand, we have already established that to perceive is not to form an image in the mind but to select by leaving out what is of no interest to the living body. What remains to be explained is how the act of selecting can result in a conscious phenomenon, understood as impersonal and objective, that is, as the possible action of a particular image.

What else can provide the explanation but the manner the necessity of actions and reactions governing matter is converted into possible actions? Already, mere observation attests that the manifestation of consciousness depends on the extent to which action affords choice. The more action is automatic the less it is conscious, a good illustration being the unconscious nature of our habitual actions. Consciousness serves no purpose at all if action is bound to happen necessarily. The observation that consciousness 
appears or disappears according as action disposes of choices or not can help us understand both the virtuality of consciousness in matter and its activation. If indeed necessity suppresses or blocks the manifestation of consciousness, it is logical to infer that a mechanism capable of suspending the necessity of matter is liable to actualize virtual consciousness into the conscious perception of images.

The inference relates consciousness to action rather than being, since it associates its manifestation to the liberation of action from necessity. Whenever the interaction of images ceases to be necessary, consciousness materializes as perception, as "a variable relation between the living body and the more or less distant influence of the objects which interest it." 29 We can thus deduce conscious perception--not consciousness itself--from the type of action connecting images. That necessity precludes consciousness establishes conscious perception as an indispensable condition of any action implicating choice. In thus inferring conscious perception from images interacting in a particular way, Bergson is perfectly consistent with his idea that perception stems from things rather than being the projection of a subject.

Placing perception in the things themselves reveals the true role of the brain, which is not to generate representation, but to convert necessity into possible action, thereby actualizing conscious perception. Bergson establishes this role by contrasting the brain with the reflex function of the spinal cord. The difference between the two is not that the brain produces representations, but that the external stimulus, unlike the immediate, involuntary reactions of the spinal cord, takes a detour via the encephalon before reaching the spinal cord and provoking a motor reaction. Short of generating representation, what else can the transit through the brain entail but a delay between reception and execution, which delays allow voluntary reaction? The primary role of the brain is thus "to delay" communication and make sure that "the peripheral excitation gets into relation with this or that motor mechanism, chosen and no longer prescribed." 30 Each time reaction is delayed, necessity is transformed into possible action. The Bergsonian interpretation moves the role of the brain from deterministic to the more positive function of instrument of freedom.

The delay between action and reaction is how time is inserted into the automatism of matter or, which is the same thing, how a breach is introduced into necessity and an ontological support is provided for conscious perception. While what is automatic shuts off consciousness, what delays automatism creates a temporal gap that affords choice, and so converts images into possible actions. The larger the temporal gap is, the more extended is the field of possible action so that "perception is master of space in the exact measure in which action is master of time." 31 
Owing to the selective nature of perception, the delay concerns only a small part of the universal interaction of all images, the part received by the senses and transmitted to the brain. As a matter of fact, sensory receptors by which light, sound, odor, taste, etc., are captured are selectively sensitive to the environment. For instance, the human eye, which is only sensitive to vibrations of certain frequency, cannot detect radiation that is outside the visible region of the spectrum. This selective nature of the senses enables the living body to detect the objects that it needs in the environment and avoid those that are detrimental. The unselected part, which is the greater part, is not delayed: it passes through and hence remains unconscious.

At this stage, there seems to be a disjunction between the images and the living body. On one side, we have stimulus captured by the senses and transmitted to the brain; on the other, we have external images. How are these images connected with the living body? In the traditional approach, the living body was assumed to connect with external objects thanks to their subjective duplicates. The latter guide its reactions: hence the traditional characterization of perception as preliminary knowledge. Since Bergson removes the subjective copy of things, how do the living body's reactions adjust to external images?

The answer is provided by the second function of the brain (other than delaying), which is to coordinate the motor ability of the body with sensory stimuli. Bergson's famous parallel of the brain with a "telephone exchange" means that, in addition to receiving messages from outside, it sends them to selected motor mechanisms. Obviously, the process co-ordinates external stimuli with motor responses but does not fully explain why the responses allow choice. The full explanation appears when we note that, by the time the stimuli reach the motor tracks, they are transformed into "nascent actions." Because a multitude of motor routes are open to the same stimulus at the same time, it is bound to "dissipate itself in innumerable motor reactions which are merely nascent." 32

Nascent actions are motor sketches, actions prefigured but not executed. As such, they are felt as invitation to act. In the words of Bergson, they are "movements begun, but not executed, the indication of a more or less useful decision, but not that constraint which excludes choice." 33 The connection of external stimuli with motor abilities in such a way that they are transformed into nascent actions instead of imparting automatic reactions is the very basis of the spontaneity of the living body. To the extent that motor sketches are given as internal affections, they operate as solicitations to act by selecting from an array of possible responses. Clearly, this type of spontaneity does not necessarily implicate self-consciousness; it is simply a motor spontaneity that is half way from mechanical response and deliberate decision. The latter presupposes and further extends spontaneous behavior so that, as a higher activity emerging from a lower motor spontaneity, deliberate decision supports Bergson's position that pure perception does 
not require a self-conscious subject. The spontaneity of the living body resulting from the internal feeling induced by nascent actions is enough to account for the activities associated with perception. At the stage of perception, "consciousness appears as a feeling...the feeling of spontaneity." 34 What makes nascent actions conscious in the form of feeling is that, as is the case with external images, they are suspended actions, and so actualized consciousness.

To assess properly the role of nascent actions, a quick contrast between Bergson and what is known as the sensorimotor theory of perception is instructive. The sensorimotor account, as developed for instance by Alva Noë and J. Kevin O'Regan, agrees on many important points with the Bergsonian theory. Thus, like Bergson, the theory rejects the idea that perception takes place in the perceiver and maintains that the brain is necessary but not sufficient to account for perception. Emphasizing the practical dimension of perception in agreement with Bergson, Noë and O'Regan write, "visual experience is not something that happens in individuals. It is something they do." 35 Moreover, this practical function stems from "a set of rules of interdependence between stimulation and movement," the very one from which Bergson derives the spontaneity of the living body. ${ }^{36}$ Accordingly, the adaptation of the living body to the environment is not effected through the cerebral replica of external objects, but through the synchronization between reception and reaction. The synchronization makes the mental duplication of objects superfluous so that perception occurs outside the perceiver. As an illustration, Noë and O'Regan compare the living body's adaptation to the environment to a missile tracking an airplane thanks to its ability to modify its behaviors in response to changes in received information.

Noë and $\mathrm{O}^{\prime}$ Regan concede that the tracking system of the missile, unlike the living body, does not perceive. Where lies the difference between the two systems? To raise such a question is to acknowledge that the sensorimotor account needs an additional element to explain perception. For, even though we have coordination between reception and movement in both cases, in the missile the coordination results in automatism, which excludes conscious perception. That is why the two authors end up by presupposing conscious perception instead of deducing it from the sensorimotor account. They say that to be responsive to and aware of the environment, the living body must, in addition to the coordination between reception and movement, "integrate its coupling behavior with its broader capacities for thought and rationally guided action." ${ }^{37}$ Instead of backing up perception, which is, after all, a primitive activity that precedes all other activities, with higher intellectual faculties, Noë and O'Regan should have inquired into the reason why the tracking missile is not consciously aware. In so doing, they would have come to the realization that, although there is coordination in both cases, in the case of the living body the coordination is 
such that it only induces nascent actions, which allow latitude of choice and with it conscious perception. In addition to coordinating stimulation with motor response, the brain inserts indetermination so that the response, instead of being automatic, is given as possible action. Needless to say, the sensorimotor account of perception misses the fact that, once the theory of the brain as an organ of representation is laid to rest, the inherence of consciousness in matter turns into a logical precondition. As soon as the inherence is admitted, it becomes easy to explain how the brain actualizes what is but dormant in matter.

\section{The Mechanism of Selection}

Noted that the coordination between incoming information and motility through nascent actions constitutes the living body as a sensorimotor unit, there remains the question of the precise mechanism by which virtual perception is converted into actual or conscious perception. For Bergson, the problem is to comprehend how the source of the stimulus that the body selects or delays stands out, becomes visible. Unfortunately, many commentators of Bergson attribute the conversion to conscious perception to some kind of action on the part of the living body. According to Leonard Lawlor, for instance, perception occurs when the light emanating from objects is reflected by the spontaneity of the body instead of being refracted. The reflection draws "a virtual image" so that "perception is a mirage of reflected light." 38 Though Bergson does characterize perception by the terms "impeded refraction," "total reflection," "effect of mirage," the truth is that perception is neither reflection, nor mirage. ${ }^{39}$ The terms are used analogically to explain the appearance of perception as reflection or mirage; they do not portray what perception is. The proof that it is about appearance in the sense of make-believe is provided by the fact that Bergson speaks of "rays," which, "instead of passing through those centers [of action], will appear to be reflected and thus to indicate the outlines of the object which emits them." 40

The terms "reflection" and "mirage" are used to illustrate why we have great difficulty in understanding perception as an objective process that goes from objects to the perceiver in contrast to the more apparent reverse process of the perceiver illuminating objects. The objective account of perception cannot dismiss the belief that the subject illuminates objects any more than the scientific knowledge of the size of the sun can alter our perception of it as a small disc. Be it noted that the seeming movement from the perceiver to the object produces an effect akin to a mirage: unlike hallucination, a mirage is really perceived except that it is not perceived where the object is. Similarly, a reflected image would not coincide with the object, which is exactly why theories of perception cannot avoid subjectivism. While perception is an objective interaction between images, it 
appears to take place inside the perceiver and then to be projected outside. As we shall soon see in some detail, the way the living body interacts with images is primarily responsible for the appearance of projection: both the capture of some of their influences and the delay of reaction create the illusion that representation comes out from the body. What is more, the intervention of memory in the centered system of perception is bound to strengthen the falsehood that perception proceeds from the subject. Let us agree, then, that the likening of perception to "an effect of mirage" is Bergson speaking, to quote one author, "in the mode of as if': by preventing total refraction, with the consequence that the luminous rays cannot pursue their way, the body acts as though it were a reflector." 41

So rectified, the operation by which Bergson explains both the appearance and the true nature of perception is rather simple. While an ordinary image acts as a passageway for the modifications emanating from all the images, the encounter of the actions of images with the living body, which Bergson defines as "zones of indetermination" and equates with a "black screen," presents a different outcome in that some of the actions cannot pass unopposed. ${ }^{42}$ In capturing some of the modifications, the senses isolate and channel them without any refraction to the brain where they are delayed, divided, and sent to selected motor paths. The purpose of the entire process is to prevent vibrations from propagating and producing immediate reactions. This ability to prevent refraction and reflection likens the body to a black screen. The whole question is to understand that this process is at the same time how the images sending the vibrations are made to protrude. According to Bergson, when the rays coming from surrounding images meet an image that acts as a black screen, and not as a reflector, the outcome is that the images shine out. To convert an unperceived image to a perceived one, Bergson writes, "it would be necessary, not to throw more light on the object, but on the contrary to obscure some of its aspects...so that the remainder, instead of being encased in its surroundings as a thing, should detach itself from them as a picture." 43

To correctly understand the operation and its outcome, let us see what would happen if the body were to throw more light on the surrounding images. It would mean that the body reacts to the rays through refraction and/or reflection, the outcome of which is that there is more light instead of less. Just as car drivers approaching from opposite directions are dazzled if they use high-beam headlights, any reflecting or refracting action of the part of the body will add more light to the surrounding images so that no particular image is distinguishable. If, however, acting as a black screen the body does not add more light to some of the vibrations reaching it, the sources from which they emanate detach themselves from all the rest. Nothing stands out in the unselected part of reality, due to the dazzling light caused by the instantaneous and all-round actions and reactions of images. Put otherwise, what the body has not selected remains translucent for lack of 
a darkening agent. By contrast, in suspending its reactions to some aspects of the surrounding images, to wit, in not adding more light, to pursue the analogy, the living body cuts and draws them out from the fused and indistinct existence of the interactions of all images. The selected aspects stick out from their flattened existence owing to the delay of reactions which, had they occurred, would leave them immersed in the surroundings. The actions and reactions of images in all their sides yield an entangled reality in which nothing is distinctly appearing. In delaying its reactions to some of these actions, the living body extracts them from the entanglement and displays them as its possible actions.

Now let us translate the physical analogy in psychological terms. Instead of acting as a reflector, the living body, we said, delays its reactions by channeling the vibrations to which it is selectively receptive through the complicated maze of the nervous system. In so doing, it lifts the neutralization of consciousness by the automatic actions and reactions of images. Because the images sending the vibrations are not reacted to, the virtuality of consciousness is actualized and images become conscious perceptions. Such a conscious appearance is not consciousness of something, but images as consciousness, as possible actions of the living body. To simplify, if we take two images, representation remains virtual because the action of each image returns as reaction, and so neutralizes representation. However, if one image holds back its reactions, the acting image appears: the suspension of necessity allows its manifestation as consciousness.

To illustrate further, let us take the example of sounds, which according to science are vibrations. The sound emitted by an object in a room bounces off from all the present objects. None of these objects hears because each reacts automatically so that the process is restricted to vibrations received and returned by all objects. As a result, no sound is distinguishable in the room and hearing remains virtual. If, however, we introduce in the room a living body, the vibrations are heard, not because the living body transforms them subjectively into sound, but because the ears capture the vibrations and channel them to the brain so that reaction is withheld. This suspension actualizes consciousness, not in the brain, but in the object emitting the vibration. This does not mean that the object hears itself for the obvious reason that necessity is suspended for the aspects that interest the living body and not for the object itself, which remains in the system of matter. The selected part is heard by the non-reacting image in the precise sense that it is given as its possible action.

The interruption of determinism cannot be realized by any mechanism resorting to action and reaction. In whichever way the mechanism is designed, action and reaction cannot but activate determinism instead of suspending it. Ruse is what is needed, the very one contrived by the living body, which is to delay reaction by sending the actions of images into a labyrinth of intricate paths that delays, divides, and distributes them to 
selected motor connections. Not only does the ruse suspend determinism, but it also does it in such a way that the object appears as the possible action of the living body.

\section{From Pure to Concrete Perception}

We saw how the living body cuts out its own possible actions in the fluid reality of the interactions of images. The operation consists in images sticking out from the surroundings and assuming individualized and fixed forms. What pure perception explains is the selection process, not the distinct and fixed appearance of images. The latter requires the intervention of another faculty, namely, memory, which then accounts for the transition from pure to concrete perception.

To begin with, the way perception is explained calls for the involvement of memory. As stated previously, all-sided actions and reactions mean that the formation of distinct images remains virtual, as it is "neutralized at the very moment when it might become actual, by the obligation to continue itself and to lose itself in something else." 44 That actions and reactions dissolve individuality also entails that constant mobility is the defining characteristic of the underlying reality. This perpetual dissolving of distinctness indicates that pure perception cannot be more than the "pure blinking of phenomena," their instant appearance and disappearance. ${ }^{45}$ To give consistency and duration to what is selected, a faculty that can contract various moments of the movement of material objects is necessary. What else could realize this contraction but memory, the very faculty that "prolongs the past into the present?" 46 Our continuity holds together in the same present moments of matter that are successive. The prolongation solidifies, so to say, what constantly appears and disappears, which is then none other than perception without memory, or, which is the same thing, materiality. In thus holding together flicking moments of pure perception, memory injects the rhythm of our duration into the perception of matter.

In light of the practical function of perception, the intervention of memory should not come as a surprise. It springs to mind that the disengagement of the living body from the rhythm of matter conditions its ability to act on matter by freely choosing its reactions. In condensing instantaneous moments, the living body obtains distinct and fixed images, thereby solidifying the flow of matter in a way appropriate to its actions. In addition to adjusting objects to the actions of the living body, the fixation imparts more intensity to the characteristics of images. The immediacy of actions and reactions posits a very relaxed, loose continuity in matter. It amounts to the doing and undoing of phenomena and accounts for their flickering appearances. Speaking of the highly diluted intensity of material phenomena, Bergson refers to a "very long history." 47 Thus, what in one 
second we perceive as red light is the history of 400 billions of successive vibrations in matter.

It follows that the qualitative nature of perception is the product of condensation of the extremely diluted continuity of matter. The qualities that we perceive do exist in matter but in a very weakened form so that they come close to constituting, without ever reaching it, a system of homogenous and quantitative vibrations. Qualities are thus not merely subjective translations; they are objective aspects of matter that our memory condenses, thereby giving them a more intense and defined appearance. We must keep in mind that what is immobilized and condensed as picturesque and stable does not cease to be vibrating inside itself. The identity and stability of the object persists so long as the internal vibrations do not cause a noticeable difference.

The attribution of qualitatively defined and stable objects to memory's condensation of the selective work of pure perception should not give rise to the charge that Bergson reintroduces a distinction between appearance and reality. True, there are no distinct objects in matter and the distinctions that our perception introduces are artificial, being valid only for the purpose of action. However, the artificiality does not subjectivize the perceived, which is of the same nature as the real: it only gives it a form appropriate to the actions of the living body. Neither selection nor condensation alters the content of what is given and both simply adjust images to the action of the living body. It is obvious for selection; it is no less obvious for condensation, since what is contracted and appears as an object with distinct qualities is the very one exiting objectively but in a more diluted manner.

To sum up, two temporal facts of memory contribute to the genesis and autonomy of the subject. (1) The contraction of the extremely rapid succession of matter by a more concentrated duration differentiates subject and object. For the theory assimilating perception to an internal copy, the distinction between subject and object originates from the projection of the duplicate as representation of external objects. As a result, space becomes the mark of externality, and hence of the distinction between subject and object, the defining character of the former being its inextensibility. As analyzed previously, such a solution makes the existence of the external world very problematic. Bergson rejects the idea of perception as spatial projection; instead, he proposes a temporal approach to the distinction between subject and object. In his own words, "questions relating to subject and object, to their distinction and their union should be put in terms of time rather than space." 48 (2) The conservation of the past generates a historically acquired identity that gives the subject precedence over the object. The insertion of past memories into pure perception subjectivizes the act of perceiving: beyond being just selection, it acquires a cognitive dimension, with the understanding that subjectivity is not the act of projecting internal states but of interpreting and enriching the present perception with past 
experience. The interpretation is how the past spontaneously moves toward the present, thereby converting the impersonal nature of pure perception into the perception of a subject.

In thus replacing the dualistic opposition between subject and object with differences in durational intensity, Bergson demarcates subject and object while at the same time maintaining the objective nature of perception. Pure perception represents the level where subject and object coincide, while concrete perception provides the higher level where the distinction between the two takes place. The classical approach lodges perception in the subject and no matter how this perception is said to join the external world, neither the existence of an external world nor the objectivity of perception can be recovered. The correct approach is to leave perception in the things themselves and show how the subject emerges from this primitive union. The theory overcomes the difficulties of traditional dualism: instead of trying to unite two substances (matter and spirit) defined as irreconcilable, it establishes their effective union at the level of pure perception and their distinction at the higher level of concrete perception subsequent to the intervention of memory.

1 George Berkeley, A Treatise Concerning the Principles of Human Understanding (New York: Dover Publications, 2003), 31.

2 Henry Bergson, Matter and Memory, trans. Nancy Margaret Paul and W. Scott Palmer (New York: The Macmillan Company, 1929), 14-15.

3 lbid., 73.

${ }^{4}$ Rene Descartes, "Meditation on First Philosophy," in Meditations and Other Metaphysical Writings, trans. Desmond M. Clarke (New York: Penguin Books, 1998), 70.

${ }^{5}$ Bergson, Matter and Memory, 81.

6 lbid., 15.

7 Ibid., 17.

${ }^{8}$ Rudolf Bernet, “A Present Folded Back on the past (Bergson)," Research in Phenomenology 35, no. 1 (2005): 60.

${ }^{9}$ Bergson, Matter and Memory, 8.

10 Ibid., viii.

11 Ibid., 27.

12 Gilles Deleuze, Cinema 1: The Movement-Image, trans. Hugh Tomlinson and Barbara Habberjam (Minneapolis: University of Minnesota Press, 1986), 56.

${ }^{13}$ Bergson, Matter and Memory, 278. 
${ }^{14}$ Malika Auvray, "Bergson, une theorie sensorimotrice de la perception," Psychologie et Histoire 4 (2003): 6 (my translation).

15 Bergson, Matter and Memory, 28.

16 Ibid., 26.

17 Jean-Paul Sartre, Imagination, trans. Forrest Williams (Ann Arbor: The University of Michigan Press, 1962), 40.

18 Ibid., 40. Maurice Merleau-Ponty too says that Bergson fails to "distinguish between consciousness and the object of consciousness." See, Maurice Merleau-Ponty, The Incarnate Subject, trans. Paul B. Milan (New York: Humanity Books, 2001), 89.

19 See Florence Caeymaex, Sartre, Merleau-Ponty, Bergson: Les Phénomenologies existentialistes et leur héritage bergsonien (New York: Georg Olms Verlag, 2005), 201.

${ }^{20}$ C. A. Van Peursen, "Henri Bergson, phénoménologie de la perception," Revue de Métaphysique et de Morale 65, no. 3 (1960): 319 (my translation).

21 Deleuze, Cinema 1: The Movement-Image, 22.

22 Sartre, Imagination, 40.

${ }^{23}$ Frédéric Worms, Introduction à Matière et Mémoire de Bergson (Paris: Presses Universitaires de France, 1997), 198 (my translation).

${ }^{24}$ Renaud Barbaras, Desire and Distance: Introduction to a Phenomenology of Perception, trans. Paul B. Milan (Stanford: Stanford University Press, 2006), 102.

25 Bergson, Matter and Memory, 43.

26 John Locke, An Essay Concerning Human Understanding (Indianapolis: Hackett Publishing Company, 1996), 148.

27 Maurice Merleau-Ponty, Nature: Course Notes from the College de France, trans. Robert Vallier (Evanston, Ill.: Northwestern University Press, 2003), 54.

28 Bergson, Matter and Memory, 297.

29 Ibid., 24.

30 Ibid., 19-20.

31 Ibid., 23.

32 Ibid., 20.

33 Ibid., 2.

34 Valentine Moulard-Leonard, Bergson-Deleuze Encounters: Transcendental Experience and the Thought of the Virtual (Albany: State University of New York Press, 2008), 22.

35 Alva Noë and J. Kevin O’Regan, “On the Brain-Basis of Visual Consciousness: A Sensorimotor Account," in Vision and Mind: Selected Readings in the Philosophy of Perception, eds. Alva Noë and Evan Thompson (Cambridge: MIT, Press, 2002), 567.

36 lbid., 568.

37 lbid., 569. 
38 Leonard Lawlor, The Challenge of Bergsonsism: Phenomenology, Ontology, Ethics (New York: Continuum, 2003), 24.

39 Ibid., 29-30.

${ }^{40}$ Bergson, Matter and Memory, p. 30.

${ }^{41}$ Caeymaex, Sartre, Merleau-Ponty, Bergson, 20 (my translation).

42 Bergson, Matter and Memory, 32.

43 Ibid., 28.

44 lbid., 28.

${ }^{45}$ Worms, Introduction à Matière et Mémoire de Bergson, 156 (my translation).

${ }^{46}$ Bergson, Matter and Memory, 279.

47 Ibid., 275.

48 Ibid., 77. 